\title{
ERZINCAN VE ÇEVRESINDE ERMENI OLAYLARI (1890-1896)
}

\section{Dr. Cengiz ÇAKALOĞLU*}

\begin{abstract}
2. 3.
\end{abstract} Ermeniler herhangi bir baskıya ma'rûz kalmadıklan gibi, aile ve iş hayatı, ticaret, mulk ve servet edinme, devlet memuriyetlerine girmede devlet desteği görmüşlerdi. Ancak, 1877-1878 Osmanlı-Rus Savaşı Ermeniler açısından bir dönüm noktası oldu. Bu savaş sonunda imzalanan Ayastefanos ve Berlin Antlaşmaları'nda Ermeniler lehinde bazı ıslahatlar yapılacağına dair hükümlerin yer alması, diğer devletlerin Osmanlı Devleti'nin iç işlerine müdahale etmelerine fursat verdi ve böylece bir Ermeni meselesi doğmuş oldu. Avrupa devletlerinin yardım ve destekleriyle bazı Ermeniler tarafından bağımsız bir Ermenistan kurmak hayaliyle Hınçak ve Taşnak gibi terör cemiyetleri kuruldu. Bu cemiyetler, Ermeni nüfusunun bulundugu yerlerde hızla teşkilatlandılar. Gerek Müslumanları ve gerekse isteklerini yerine getirmeyen Ermenileri sindirmek amacıyla, küçük çeteler şeklinde adam kaçırma, yol kesme, soygun, adam öldürme, rrza tecavuz gibi çeşitli eylemlere başladılar.

Erzincan ve çevresi de eskiden beri Ermenilerin yaşadıkları yerlerdendi. Ancak, ülkenin diğer yerlerinde olduğu gibi, Erzincan'da da Ermeni nüfus Müslüman nüfusa kıyasla azınlıkta kalmaktaydı. Mesela, 1890'lı yılların başlarında sancaktaki Ermeni nüus, enel sancak nüfusunun \% 20'sinden azd1 ${ }^{1}$. Bu tarihlerde Erzurum vilayetine bağlı bir sancak merkezi olan Erzincan aynı zamanda IV. Ordu'nun da merkezi olması hasebiyle askerî açıdan önemli bir şehirdi.

Erzincan ve çevresindeki Ermeni çetelerinin, faaliyetlerini özellikle 1890 yılından itibaren artırdıkları görülmektedir. Bu tür çeteler için en uygun faaliyet alanı sancak dahilinde Ermeni nüfusunun en yoğun olduğu Kuruçay kazasına bağlı Armudanlar bucağıydı. Burası, Ermeni eşkıya çetelerinin genellikle karargah yaptıkları Divriği'ye bağlı Pingan köyüne yakın olduğundan Ermeni çetecileri Armudanlar'1 faaliyetleri için çok uygun bir yer saymışlardı. 1891 yılında burada bir olay meydana geldi. Ceteciler, kendilerine karşı çkan Aharon adında bir dava vekilini öldürmeye karar verdiler. Komitenin kararını Büyllk Armudan halkından Ilbısogullarından üç komiteci yerine getirdi. Kuruçay Kaymakamı Ahmet Bey, aynı köyden Ömer Pehlivan'ı gerçeği araştırmakla görevlendirildi. Ancak, gizli görevi Ermeniler tarafından ögrenilen Ömer Pehlivan, bir Ermeninin evinde düzenlenen bir

* Atatürk Üniversitesi, Erzincan Eğitim Fakültesi, Araştırma Görevlisi.

${ }^{\prime}$ Vital Cuinet, La Turguıe d'Asie, I, Paris1892, s. 210. 
ziyafette fecî şekilde öldürüldü. Cesedi de evinin bacasının yanına getirilip üzerine gazyağı dökülerek yakıldı ${ }^{2}$. Ayrıca, cinayeti mahallî hükủmete ihbar eden Serkis ile oğlu yine aynı çete mensupları tarafindan öldüruldügu gibi, Hüseyin adlı bir bekçi de yaralandı. Kısa bir süre sonra, olaylarla ilgisi olan Papas Karabet, Kiragos, Abkar, İranus, Teohari, Kirkor, Kigork, Manuel, Sahak, Agop, Migırdıç, Kazar, Vartan, Agik, Minas ve Moşeh isimli onaltı kişi ${ }^{3}$ silahlarıyla birlikte ele geçirilerek mahkemeye sevkedildiler".

Diğer yandan Illiç köyü mektebinde ögretmenlik yapan Ermeni cemiyeti reisi Kuruçaylı Haçatur'un evinde yapılan aramada bazı zararlı evrak ele geçirildi. $\mathrm{Bu}$ evrak ve kendisinin sorgusundan Kuruçay kazasındaki Ermeni köylerinden bazılarının Ermeni cemiyetine bağlı olduklanı ve bir karışıklık çıkarmak niyetinde bulundukları anlaşıldı. ${ }^{5}$. Onun verdiği bilgilere dayanılarak arkadaşları da ele geçirildi. Bunlardan biri de Küçük Armudan'dan Ohanyan Artin oğlu Çulha Nişan idi. Culha Nişan'ın suçu sabit görülerek múebbet hapse mahkum edildi'. Bu havalideki Ermeni faaliyetlerinin yoğunlaşması üzerine, bölgedeki askerî tedbirler artırıldı ve Çardaklı Boğazı'nda bulunan süvari müfrezesinin Refahiye, Kuruçay ve Kemah arasında dolaşması kararlaştırıld ${ }^{7}$.

Erzincan şehir merkezindeki Ermeni çetecileri de boş durmuyorlard. Komitenin isteklerini kabul etmeyen Azaplar oglu Armin adlı bir Ermeni bir gece evine giderken komiteciler tarafindan tabancayla yaraland ${ }^{8}$.

Erzincan çevresinde faaliyet gösteren çete başlarından birisi de, Rupen adlı bir Ermeni idi. Rupen ve çetesi Kemah'a bağlı Garni köyünün üst tarafındaki yüksek ve sarp dağda bulunan Çanlı Manastır'ı karargâh haline getirmişler ve Türklere sarkıntılığa başlamışlardı. Rupen çetesinin saldırılarından biri de, 1894 yılında meydana geldi. Malatya'ya gitmekte olan askerî kaymakamlardan Reşit Bey'in yolunu kesen çete mensupları kendisini kaçırdıkları gibi, emrindeki çavuşu da öldürdüler. Ağa isimli birinin durumu bildirmesiyle mahallî hükümet durumdan haberdar oldu. Çetenin karargahı Çanlı Manastır kuşatılarak Reşit Bey kurtarıldı̆̆ı gibi, çetenin bütün üyeleri de ele geçirildi. Rupen ve adamları Erzincan'da yapılan yargılama sonucunda idam edildiler. Reşit Bey'in kurtarılmasında rolü olan Ağa ise, daha sonra davetine uyduğu Erzincan'da bir Ermeni'nin evinde öldürüldü' .

Bütün bu başarılı tedbirlere rağmen bölgedeki Ermeni faaliyetlerinin devam ettiği görülmektedir. Nitekim, Armudanlı Haci Kalost ve arkadaş̧arı Zakar ve Eğinli

\footnotetext{
${ }^{2}$ Ali Kemali, Erzincan, İstanbul 1992, s. 89.

${ }^{3}$ Hưseyin Nâzım Paşa, Ermeni Olayları Tarihi, I, Ankara 1994, s. 15.

${ }^{4}$ BOA, BEO, Erzurum Telgraf Giden, Defter No: 928, s. 64.

${ }^{5}$ BOA, BEO, Erzurum Telgraf Giden, Defter No: 928, s. 56.

${ }^{6}$ Hüseyin Nâzım Paşa, Ermeni Olayları Tarihi, I, s. 35.

${ }^{7}$ BOA, BEO, Vilayat Gelen-Giden, Erzurum, Defter No: 128, s. 13; Y. A. Hus. 252/I 15.

${ }^{8}$ Ali Kemali, Erzincan, s. 90.

${ }^{9}$ Ali, Kemali, Erzincan, s. 90-91.
} 
Kokakçıyan Sahak ve Canik isimli kişiler kırlarda ve dağlarda eşkıyalık yapıyorlardı. Adı geçen çete mensupları 1895 Ağustosunda Refahiye Kaymakamının yolunu keserek mal ve eşyasını gaspettiler ${ }^{10}$.

1895 yllında olayların mahiyeti değişmeye başladı. Artık Ermeni çetecilerinin hedefi, şehir merkezlerinde büyük olaylar çıkmasına sebep olacak eylemler gerçekleştirmekti. Nitekim, 1895 yılının Ekim ve Kasım aylarında Doğu ve Güneydoğu Anadolu Bölgeleri'nin hemen hemen bütün şehir merkezlerinde Ermenilerin sebep oldukları büyük karışıklıklar meydana geldi. Bu şehirlerden birisi de Erzincan idi.

Pazartesi günleri şehirde pazar kuruluyordu. Ermeni komitecileri şehrin böyle kalabalık olduğu bir günde karışıklık çıkarmayı planladılar. 21 Ekim 1895 Pazartesi günü eylem günü olarak tesbit edildi. Belirtilen günde herkes alışverişiyle meşgul iken saat üç civarında Buğday Meydanı denilen yerde bir imam Ermeni fedaileri tarafindan başına kurşun sıkılmak suretiyle öldurüldü. Aynı anda diğer fedailer de harekete geçerek çeşitli yerlerde kurşun atmaya başladılar. Bu surada Müslümanlardan bazıları öldü veya yaralandı" . Silahsız ve hazırlıksız yakalanan pazardaki Müslümanlar satmak için pazara getirmiş oldukları sepet sopalarıyla kendilerini korumaya çalıştılar. Ermeni fedaileri devriye gezen askerlere ve karışıklık üzerine dışarıya çıkan IV. Ordu Komutanı Müşir Mehmed Zeki Paşa'ya da ateş $\operatorname{açtılar~}^{12}$. Ahalinin heyecana gelmesi ile şehirde büyruk bir karışıklık çıktı. Asker ve zabtiye tarafından karışıklığn önüne geçilmesi için büyưk gayret sarfedilmişse de, Ermenilerin toplandıkları sokaklardan ve evlerinin damlarından ve pencerelerinden ateşe devam etmelerinden dolayı olaylar ancak bir-iki saat sonra kontrol altına alınabildi. Diğer yandan bazı Ermeniler Erzincan koylerine saldırarak bir hayli hayvan ve eşya gasbettiler. Amaçları köylerde de olay çkarmak olduğundan buna meydan verilmeden icab eden yerlere süvari müfrezeleri çıarıldı ${ }^{13}$. Sonradan yapılan incelemelerde, Ermenilerin köylerde de buiyük hazırlıklar yaptıkları anlaşılmıştır. Mesela, Mitini köyünde Ermenilerin evlerinin üzerinde mazgallı siper ve metrisler ile bir damdan bir dama kolaylıkla geçmek için köprü gibi geçiş vasıtaları tesis ettikleri görülmusşür ${ }^{14}$.

Erzincan Polis Komiserliği’nin vilayete gönderdiği 22 Ekim 1895 tarihli telgrafından bu olaylar sırasında Müslümanlardan 5 ve Ermenilerden 50 kişinin oldüğü anlaşılmaktadır ${ }^{15}$.

\footnotetext{
${ }^{10}$ Hüseyin Nâzım Paşa, Ermeni Olayları Tarihi, 1, s. 15.

${ }^{11}$ BOA, Y. A. Hus. 338/17.

${ }^{12}$ BOA, Y. Mtv. $130 / 37$.

${ }^{13}$ BOA, Y. A. Hus. 338/17.

${ }^{14} \mathrm{BOA}$, I. Askeri, $1313 \mathrm{~B} / 3$.

${ }^{15}$ BOA, Y. A. Hus. 338/18; Hüseyin Nâzım Paşa, Ermeni Olayları Tarihi, s. 96.
} 
Şehir merkezindeki karışıklığın önüne geçilmiş olmakla birlikte, ulema, müderris ve eşraftan onüç ơnde gelen Erzincanlı'nın Babıali'ye çekmiş oldukları 10 T. Evvel 311 (22 Ekim 1895) tarihli bir telgraftan gerginligin ertesi gün de devam ettiği anlaşılmaktadır. Bu telgrefta yer alan sadeleştirilmiş olarak " ... Bunların turlu hayasızlıklarını ve kötülukklerini derhal mahva kadir isek de Padişahımız ve Hükümetimize olan bağlılı̆̆ımıdan dolayı şimdiye kadar bunların türlü hakaretlerine tahammul ettik. Fakat, kottülükleri artık tahammülün dıssina çkt. Ermenilerin silahlart toplanmaz ve cemiyetleri dağutumaz ise, hem onlar mutlak bir fenaltk çkarır ve hem de zaten galeyanda bulunan İslamlar bir kat daha heyecana gelerek içimizdeki bazı cahiller intikam almaya kalkarsa mazallah büyük bir karışıklık çıkar... ${ }^{16 \%}$ ifadeleri, olaylar sırasında Müslümanların tavrını göstermesi açısından oldukça dikkat çekicidir.

Diğer yandan, Erzincan'daki karışıklıktan istifade eden Dersimli bazı eşkıya grupları Erzincan köylerine çeşitli saldırılar yapmaya başladılar. Bu sırada Erzincan Mutasarrıflığ görevinde bulunan Namık Paşa, Erzurum Valisi Rauf Paşa aracılığıyla Babıali'ye müracaat ederek, halkın heyecanının yatıştırılmasına en acil çare olarak Erzincan ve bağlı yerlerde sıkıyönetim ilan edilmesi teklifinde bulundu. Anadolu Islahatı Mưfettişi Mưşir Ahmed Şakir Paşa da, aynı görüşteydi ${ }^{17}$. Ancak, olayların perde arkasındaki isimlerden biri olan Erzincan Marhassa Vekili Kigork ${ }^{18}$ ve bazı Ermeni ơnde gelenlerinin mahallî hükümete giderek itaat ve bağlılıklarını bildirmeleri üzerine sıkıyönetim ilanından vazgeçildi ${ }^{19}$. Bununla beraber, Ordu Komutanı Müşir Mehmed Zeki Paşa'nın teklifleri doğrultusunda, 25 Ekim 1895'te süvari alaylarının hayvan eksikliklerinin tamamlanması için bir Padişah iradesi çıktı $^{20}$. Şehirdeki jandarmaların yetersizliğinden dolayı, geçici olarak 150 jandarma istihdam edildi ${ }^{21}$.

Erzincan şehir merkezinde 21 Ekim'deki bu karışıklıktan sonra, 8 Kasım 1895 Carşamba günü bir olay daha meydana geldi. Belirtilen günde İskender Hamamı civarında Ermeni fedaileri tarafindan birkaç el silah atıldı. Ermenilerin hükümet, karkol ve bazı mahalleri bastığı şeklindeki bir şayia Müslümanların heyecanlanmasına sebep oldu. İslam ahali çarşı ve pazardan evlerine kaçmaya başladi. Ancak, alınan tedbirler sonuunda durum beş-on dakika zarfinda kontrol altına alınarak asayiş sağlandı ${ }^{22}$. Erzurum Valisi Rauf Paşa"nın ifadesinden bu karışıklık sırasında 4 kişinin öldüğü ve 1 kişinin yaralandığı anlaşılmaktadır ${ }^{23}$.

\footnotetext{
${ }^{16} \mathrm{BOA}, \mathrm{Y} . \mathrm{Mtv} .130 / 37$.

${ }^{17}$ BOA, Y. A. Hus. 338/35.

${ }^{18}$ BOA, MV. 85/125.

${ }^{19} \mathrm{BOA}$, I. Hususi, $1313 \mathrm{Ca} / 1$.

${ }^{20} \mathrm{BOA}$, I. Hususi, $1313 \mathrm{Ca} / 20$.

${ }^{21}$ BOA, Y. A. Hus. 338/35; I. Askeri, $1313 \mathrm{~B} / 12$.

${ }^{22}$ BOA, Y. Mtv. 131/120; İ. Hususi, $1313 \mathrm{Ca} / 74$.

${ }^{23} \mathrm{BOA}$, İ. Hususi, $1313 \mathrm{Ca} / 74$.
} 
Erzincan'daki bu olayların yanısıra, günümüzde Erzincan'a bağlı kazalarda da Ermeniler tarafindan çeşitli olaylar tertiplendi. 11 Ekim 1895 tarihinde Refahiye'de bir olay meydana geldi. Devriye gezen 7-8 zabtlye erine bir grup Ermeni eşkıyası tarafından ateş açılması ve zabtıyelerden Ali Onbaşı'nın bacağından yaralanması Refahiye'deki karışıklığın sebebi oldu ${ }^{24}$. Bu olay sırasında Müslümanlardan 1 kişi öldü ve 16 kişi yaralandı. Ermenilerden ise 18 kişi öldü ${ }^{25}$. Diģer taraftan 24 Ekim 1895'te Refahiye'deki Rum ahali tarafından Sadarete çekilen bir telgrafta, 400 kadar Ermeni eşkıyasının Refahiye'ye bağlı bir köyde bir Rum manastınnı basıp Rumlan katliama başladıkları şeklinde bir şikayet olmuşsa da, yapılan incelemeler sonucunda bunun asılsız olduğu anlaşıldı ${ }^{26}$.

9 Kasım 1311 (21 Kasım 1895)'te Tercan'a bağlı Mans köyü (şimdiki Çayırlı ilçesi) Müslümanları öşürden Ziraat Bankası'na ait hisseyi Tercan'a gơtürürlerken Ermeni eşkıyası tarafindan dövülmeleri ve soyulmaları, yine Tercan'a bağlı Timik köyünde 20 silahlı Ermeni eşkıyasmın Hedikli aşiretinin ileri gelenlerinden birkaçına hücum ederek yaralamaları gibi olaylar yüzünden Tercan şehir merkezinde de bülylik bir karışıklı çıktı ${ }^{27}$. Tercan'daki bu olayda Müslümanlardan 25 kişi öldü, 5 kişi yaralandı, Ermenilerden ise, 140 kişi öldü ve 42 kişi yaralandı ${ }^{28}$.

1895 yılında meydana gelen diger olaylar sırasında Kuruçay'da Müslümanlardan 2 kişi öldü ve 3 kişi yaralandı. Ermenilerden ise, 9 kişi öldü ve 5 kişi yaralandı. Kemah'ta meydana gelen olayda Ermenilerden 4 kişi öldü, 5 kişi yaralandi ${ }^{29}$.

1896 y1lunda ise, Egin'de buyduk bir olay meydana geldi. Olaylardan önce Eğin'e İliç ve Divriği gibi çevre kazalardan Ermeniler gelerek toplanmaya başlamışlardı. Buradaki eşkıyanın başı, Kasap oğlu Manuk adlı biri idi. Ermenilerin son günlerdeki tutum ve davranışlarından, kilise ve evlerinde yaptıkları toplantılardan bir ayaklanma çıkaracakları anlaşılmıştı. Bunun üzerine, Ermeni ve Müslümanların önde gelenleriyle kazanın çeşitli daire müdürleri hükümete çağrılmış ve nasihatler verilmişti. Bu nasihatlere rağmen Ermeniler 13 Eylül 1896'da Köybaş adındaki kiliselerinde toplandılar. Kiliseden çıktıktan sonra dükkanlarını açmayıp evlerinde silahları ellerinde hazır beklemeye başladılar. Diğer bir kısmı da, kilisenin üst tarafindaki buyü̈k taşlara çekildiler. Birden askerler üzerine ateş etmeye başlamalarıyla şehirde büyưk bir karışıklık çıktı. Evlerindeki Ermenilerin de dışarı çıkmasıyla ayaklanma her tarafa yayıldı. Bu sırada olayı duyarak kasabaya gelmekte olan aşiretlerle Ermeniler arasında çatışma çıktı. Diğer taraftan, Ermeniler tarafından

\footnotetext{
${ }^{24}$ Mehmet Hocaoğlu, Tarihte Ermeni Mezâlimi ve Ermeniler, İstanbul 1976, s. 292.

${ }^{25}$ Hüseyin Nâzım Paşa, Ermeni Olayları Tarihi, I, s. 171.

${ }^{26} \mathrm{BOA}$, Y, A. Hus. 338/33; Y. A. Hus. 338/54.

${ }^{27}$ Mehmet Hocaoğlu, Tarihte Ermeni Mezâlimi ve Ermeniler, s. 292.

${ }^{28}$ Hüscyin Nazım Paşa, Ermeni Olayları Tarihi, I, s. 171

${ }^{29}$ Hüseyin Nazım Paşa, Ermeni Olayları Tarihi, I, s. 171.
} 
büyük bir yangın çıkarıldı. Sehirdeki askeri birliklerin yanısıra, diğer inzibat gụçlerinin büyük gayretleri sonucunda olaylar ertesi gün kontrol altına alındı.

Olaylar sırasında Müslümanlardan 11 kişi öldu, 26 kişi yaralandı. Ermenilerden ise, 581 kişi oldu, 48 kişi yaraland. Ölenler arasında eşkıya başı Manuk da bulunuyordu. Şehirdeki yangında $622 \mathrm{ev,} \mathrm{100'} \mathrm{ün} \mathrm{üzerinde} \mathrm{dukkan} \mathrm{ve}$ Ermeni kilisesinin ahşap kısmı yandı. Ancak, asıl Eğin çarşısı askerler tarafindan korunduğu için burada Ermenilerin yangın çıkarmalarına engel olundu ${ }^{30}$. Olayların İstanbul'a iletilmesi üzerine 7 R. Ahir 1314 (15 Eylul 1896) tarihinde bir Padişah iradesi çıktı. Bu iradede; Eğin'de meydana gelen heyecanın derhal yatıştıılması ve etrafa sirayetine engel olunması için lüzumu kadar askerin derhal Eğin'e sevk edilmesi, Ermenilerin her türlü şekavetlerinin önlenmesi, civardaki aşiretlerin kontrol altında tutulması hususları belirtiliyor ve IV. Ordu Komutanı Mehmed Zeki Paşa'ya mahallî redif askerlerini silah altına alma izni veriliyordu ${ }^{31}$.

Sonuç olarak, özellikle 1890 yllından itibaren yoğunlaşmaya başlayan Erzincan ve çevresindeki Ermeni çete faaliyetlerinin 1895 yllında genel bir Ermeni isyanı şekline dönüștügü görülmektedir. Anadolu'nun diğer yerlerinde meydana gelen olaylarda olduğu gibi, buradaki olayların da tesadufí değil, planlı olaylar olduğu kesin olarak anlaşılmaktadır. Hiçbir yerde çoğunlukta olmayan Ermenilerin böyle olaylar tezgahlamaktaki amaçları şüphesiz, Müslümanları galeyana getirerek çok sayıda Ermeninin öldürulmesi ve bunun sonucunda bir Avrupa müdahalesini sağlamaktı. Yoksa silahlı mücadele ile hiçbir sonuca varmaları beklenemezdi. Hele, Erzincan gibi bir ordu merkezinde bu hiç mümkün değildi. Ermeni çetecileri, Müslümanları galeyana getirecek her yolu denemişlerdir. Mesela, Erzincan'daki olayların başlamasına, halkın çok sevdiği bir imamın öldürülmesi sebep olmuştur. Diğer yerlerdeki durum da bundan pek farklı değildir. Müslüman ahalinin bu Ermeni oyununa gelmemeye itina göstermelerini ve güvenlik kuvvetlerinin bütün çabalarına rağmen, olaylardan birçok kiş̧i zarar görmüştür.

\footnotetext{
${ }^{30}$ Mehmet Hocaoğlu, Tarihte Ermeni Mezâlimi ve Ermeniler, s. 242-243.
}

${ }^{31}$ BOA, İ. Dahiliye, 1314 R - 6. 